Article

\title{
Lipophilicity as a Central Component of Drug-Like Properties of Chalchones and Flavonoid Derivatives
}

\author{
Teodora Constantinescu ${ }^{1}$, Claudiu Nicolae Lungu ${ }^{2, * \mathbb{D}}$ and Ildiko Lung ${ }^{3}$ \\ 1 Department of Chemistry, Faculty of Pharmacy, Iuliu Hatieganu University, 400012 Cluj-Napoca, Romania; \\ teo_farma@yahoo.com \\ 2 Department of Chemistry, Faculty of Chemistry and Chemical Engineering, Babes-Bolyai University, \\ 400028 Cluj-Napoca, Romania \\ 3 National Institute for Research \& Development of Isotopic and Molecular Technologies 67-103 Donath street, \\ 400293 Cluj-Napoca, Romania; ildiko.lung@itim-cj.ro \\ * Correspondence: lunguclaudiu5555@gmail.com; Tel.: +40-(0)-742-255-099
}

Received: 11 March 2019; Accepted: 10 April 2019; Published: 17 April 2019

check for updates

\begin{abstract}
Lipophilcity is an important physico-chemical parameter that influences membrane transport and binding ability to action. Migration distance following complete elution of compounds was used to calculate different lipophilicity-related parameters. The aim of this study is to show that lipophilicity is a central component of thiazole chalcones and flavonoid derivatives regarding their drug-like properties. Experimental and computational methods were used. This study considers 44 previously synthesized compounds (thiazole chalcones, flavanones, flavones, 3-hydroxyflavones, and their acetylated derivatives). The concerned compounds have shown antitumoral hallmarks and antibacterial activity in vitro. The experimental method used to determine compounds' lipophilicity was the reverse-phase thin layer chromatography (RP-TLC). Lipophilicity related parameters-isocratic retention factor $\left(\mathrm{R}_{\mathrm{M}}\right)$, relative lipophily $\left(\mathrm{R}_{\mathrm{M}}{ }^{0}\right)$, slope $(b)$, chromatographic hydrophobic index $\left(\varphi_{0}\right)$, scores of principal components $\left(\mathrm{PC} 1 / \mathrm{R}_{\mathrm{M}}\right)$-were determined based on reverse-phase chromatography results.
\end{abstract}

Keywords: lipophilicity; retention factor; chalcones; QSAR; chromatography; drug design

\section{Introduction}

Lipophilicity is an important feature of molecules in pharmaceutical, biochemical, and medical chemistry fields. Lipophilicity applications include drug design, route of administration and chromatographic separation. The hypothesis of $\mathrm{pH}$-partition asserts that the absorption of ionizable drugs takes place where the local $\mathrm{pH}$ provides the maximum concentration of the non-ionized form relative to the ionized form concentration. In addition, lipophilicity is a physico-chemical parameter that affects the affinity of a molecule for binding sites and passive transport through biological membranes [1-4]. Affinity of molecules for a medium is often determined as a partition coefficient between water and an immiscible solvent, expressed as a decimal logarithm of the partition coefficient $(\log \mathrm{P})$ in two non-miscible solvents (e.g., water-isopropanol, water-n-octanol) [5-7]. Partition coefficient is often used in structure-activity relationships (SAR) and quantitative structure-activity relationships (QSAR) [8,9]. Some studies have described significant relationships between the determination of lipophilic parameters and the chemical structure, bioactivity, and the pharmacokinetic properties of the biologically active compounds [10]. Lipophilicity of a drug molecule is of particular importance due to its impact on the metabolism, pharmacokinetics, pharmacodynamics, and molecular toxicity of molecules. It correlates with the absorption, distribution, metabolism, excretion, and molecule toxicology (ADMET) processes [11-16]. 
Generally, there are two classes of methods developed for log P determination: Computational and experimental. There are many computational variants for predicting this property, using simple methods based on a small number of descriptors up to sophisticated neural network algorithms and involving thousands of correction factors. These methods can be greatly improved by local corrections; it is essential to compare the results with those provided by experimental methods [17,18].

Although RP-HPLC represents a very good method because of its good accuracy, low sample consumption, on-line detection, and its ability to perform measurements even in a presence of a mixture, the reverse-phase thin layer chromatography (RP-TLC) method has numerous advantages such as simplicity of the equipment, extremely low mobile phase usage, high transfer rate, and low cost of analysis. The RP-TLC method can also be used for compounds with increased lipophilicity. To describe the solute retention constants, the $\mathrm{R}_{\mathrm{M}}$ parameter shows a very good linear correlation with log $\mathrm{P}$ for neutral and ionic compounds. Another parameter of hydrophobicity is $R_{M}{ }^{0}$, sometimes preferred to the $R_{M}$ parameter. $R_{M}{ }^{0}$ is the $0 \% v / v$ extrapolated value of the organic modifier for estimating the solute partition between water and the non-polar stationary phase as measured in lipophilic solute. Another parameter, $\mathrm{C}_{0}$, expresses the concentration of an organic change in the mobile phase for which the distribution of the solute between the two phases is equal. One of the essential elements of the chromatographic system, the mobile phase, has a significant role in chromatographic behavior of different solvents $[2,19,20]$.

The term chalcone is used to name compounds characterized by the presence of 1,3-diphenyl-2propen-1-one subunit [21]. Chalcones and their derivatives exhibit many activities (anticancer, anti-inflammatory, antioxidant, cytotoxic, antibacterial, analgesic, antipyretic, antihepatotoxic, antimalarial, and anti-allergic) [22-24]. Chalcones play the role of pharmacophore in many natural products such as cumarin, flavokawain, milepachin, and xanthohumol [25]. Flavanones, 2-aryl chroman-4-one, have numerous biological properties (anticancer, antimicrobial, anti-inflammatory, antiviral, etc.) [26]. Flavones or 2-phenylchromones are present in many natural products and represent a significant group of oxygen heterocycles, present in plants as secondary metabolites. The synthesis of flavones has a particular interest due to the biological activities of these compounds-anti-inflammatory, anti-estrogenic, antioxidant, anti-cancer, antiretroviral, antihypertensive, antimicrobial, anti-diabetic, anti-allergic, and chemopreventive properties have promoted numerous ways in flavones synthesis $[9,27]$.

The thiazole nucleus is an important component for a large number of therapeutic agents with anticancer, anticonvulsant, antifungal, and antibacterial properties. The heterocycle presents applications for the synthesis of new biologically active compounds with cardiotonic, fungicidal, and antiretroviral properties. Also, thiazole may be a subunit used in the synthesis of novel molecules used in the treatment of neurodegenerative diseases (Parkinson's, Alzheimer's). This class of heterocyclic compounds is present in numerous biologically active molecules, such as sulfatiazole (antimicrobial), ritonavir (antiretroviral), bleomycin (anticancer), and meloxicam (anti-inflammatory) [6,28].

Since flavonoids and thiazole compounds exhibit numerous biological activities, and lipophilicity is an essential parameter for pharmacokinetics, pharmacodynamics, and molecular toxicology, the aim of the current study was to determinate the lipophilicity of 44 compounds (thiazole chalcones, flavanones, flavones, 3-hydroxyflavones, and their acetylated derivatives) previously synthesized by us using experimental and computational methods in order to evaluate this central component of drug-like properties. Keeping in mind the antitumoral activity of the synthesized compounds, lipofilicity is an important parameter to indicate whether these compounds may constitute a starting point for the development of novel antitumoral agents. 


\section{Results and Discussion}

\subsection{Chromatographic Evaluation}

The structure of 20 chalcones $(\mathbf{1 a}-\mathbf{t})$ was substituted with hydroxy or methoxy groups in ortho and/or para positions of acetophenone and with electron donor groups (methoxy, metyl), unsubstituted or substituted with electron acceptor groups (chlorine) in the para-position of the phenylthiazole. The basic structure is that of 1,3-difenyl-2-propen-1-one, then the retention differences are attributed to functional groups and their positions at level of the two subunits. In the case of hydroxychalcones, retention capacity is influenced by the nature of substituents at para-position of phenylthiazole. For para hydroxychalcones, the highest retention capacity is represented by chlorine-substituted chalcone (1c) in para position of phenylthiazole, followed by methyl-substituted chalcone (1b) and unsubstituted phenyl, respectively (1a). The lowest retention capacity is represented by chalcone substituted with a methoxy group (1d). Compared to the chalcone substituted in ortho position of acetophenone, chalcones with a hydroxy group in para position have a lower retention capacity and a higher hydrophilic character. This can be explained by the ability of ortho hydroxylchalcones to form hydrogen-bonding bonds with the carbonyl group on the propene-2-one moiety. In the series of ortho hydroxychalcones, the highest retention capacity is shown by the chlorine-substituted compound in para position of phenylthiazole (1g). As with para hydroxychalcones, retention capacity of ortho hydroxychalcones varies in the order 1g $>$ 1f $>1$ e $>$ 1h. Substitution with a methoxy group increases hydrophilia of the molecule.

For para methoxychalcones, the highest retention capacity was shown by para chlorine-substituted chalcone (1k) of phenylthiazole; the order of increasing in retention capacity is $\mathbf{1 k}>\mathbf{1} \mathbf{j}>\mathbf{1 i}>\mathbf{1 1}$. The most hydrophilic paramethoxychalcone is the one substituted with a methoxy group on phenylthiazole (11). For ortho, para dimethoxychalcones (1m-p), and ortho methoxychalcones, the order of decreasing retention capacity is similar to that of para methoxychalcones. Among methoxychalcones, the highest retention capacity was in para methoxychalcones, followed by ortho methoxychalcones, respectively. Inclusion of a methoxy group on acetophenone results in decreases in retention capacity. Replacement of hydroxy group in para position of acetophenone with methoxy determines the increase of retention capacity due to decrease in its polarity. When replacing hydroxyl group with methoxyl in ortho position of chalcones, the result is a decrease in retention capacity. This is explained by the bonds formed between ortho substituent of acetophenone and the carbonyl group. Among previously synthesized chalcones, the lowest retention capacity was observed in para hydroxychalcones. Compound 1d is the most hydrophobic of the 20 thiazole chalcones.

In the synthesized thiazole flavanones $(\mathbf{2 a}-\mathbf{d})$, lipophilicity is influenced by the nature of the substituent in para position of phenylthiazole. The basic subunit of flavanones, 2-aryl-chroman-4-one, changes the retention capacity compared to orthohidroxychalcones from which they are synthesized; the order of increase in retention capacity is $\mathbf{2 d}<\mathbf{2 a}<\mathbf{2 b}<\mathbf{2} \mathbf{c}$. The highest retention capacity is represented by chlorine-substituted flavanone in para position of phenylthiazole $(2 \mathrm{c})$; this represents the most lipophilic flavanone. The most hydrophilic flavanone is the compound with a methoxy group in para position of phenylthiazole $(\mathbf{2 d})$.

Flavones and 3-hydroxyflavones (3a-h) have the common structure of 2-aryl-chromen-4-one. Lipophilicity of molecules depends on the nature of substituents in para position of phenylthiazole and on the presence or absence of hydroxy group in position 3 of chromene. For thiazole flavones, the retention capacity of compounds increased in the order $\mathbf{3} \mathbf{c}>\mathbf{3 b} \geq \mathbf{3} \mathbf{d}>\mathbf{3 a}$. The highest retention capacity is shown by chlorine-substituted flavone in para position of phenylthiazole (3c). Unsubstituted flavones on phenylthiazole are the most hydrophilic (3a). In the case of 3-hydroxyflavones, the highest retention capacity was observed at the compound substituted by chlorine on phenylthiazole $(\mathbf{3 g})$. The most hydrophilic compound is the unsubstituted on phenylthiazole (3e). Compared to flavones, 3-hydroxyflavones have a lower retention capacity due to hydrophilicity, determined by the hydroxyl group. 
In the case of acetylated derivatives (4a-1), obtained by acetylation of hydroxyl groups, a decrease in polarity of compounds and a decrease in retention capacity in reverse phase determinations was observed. For this reason, experimental determination of lipophilicity was performed at other concentrations of isopropanol, by water mixture.

For acetylated derivatives, the lipophilicity of the compounds is influenced by the basic structure of the molecules (1-3-difenyl-2-propen-1-one or 3-hydroxyflavones) and the nature of para substituents of the phenylthiazole. In case of chalcones derivatives, lipophilicity is also influenced by the position of acetate group on acetophenone. Retention capacity varied: $4 \mathrm{c} \geq \mathbf{4 b}>\mathbf{4 g}>\mathbf{4 k}>\mathbf{4 f}>\mathbf{4 a}>\mathbf{4 d} \geq$ $4 \mathbf{j}>4 \mathbf{e}>\mathbf{4 h}>\mathbf{4 i}>4 \mathbf{l}$. The higher retention capacity was shown by the acetylated derivatives of chlorine-substituted para hydroxychalcone in para position of phenylthiazole (4c), and the lower was the methoxy substituted 3-hydroxyflavone derivative in para position of phenylthiazole (4h).

\subsection{Computational Evaluation}

In order to evaluate correlation between lipophilicity and compounds structure, a multiple linear regression (MLR) model was developed (Figure 1) [29]. $R_{M}{ }^{0}$ was chosen as dependent variable, while for independent variables, a variety of molecular descriptors were used accordingly with Topoliss-Costello rule. Data were split randomly, into a training set and a dataset equally. The model was internally and externally validated (see Supplemental Materials). S, $\mathrm{R}^{2}$, and $\varphi^{0}$ have also been considered, but correlations obtained were not as high as for $\mathrm{R}_{\mathrm{M}}{ }^{0}$. The obtained model had a Pearson correlation $r=0.873$, Pearson correlation squared $r^{2}=0.7619$, Spearman rank correlation $\rho=0.874$, cross validated square $q=0.761$, mean squared deviation $(M S D)=0.0162$, and $y=0.530798+0.761964 x$. Interaction model using neural network regression (NNR), (random seed 3449287299, max training epochs 1000 , learning rate 0.30 , output layer learning rate 0.30 , number of neurons first hidden layer $=$ 3 , using $\mathrm{N}$-fold cross validation $\mathrm{N}=10$, percentage split 66), retrieved a Pearson correlation of $\mathrm{r}=0.971$.

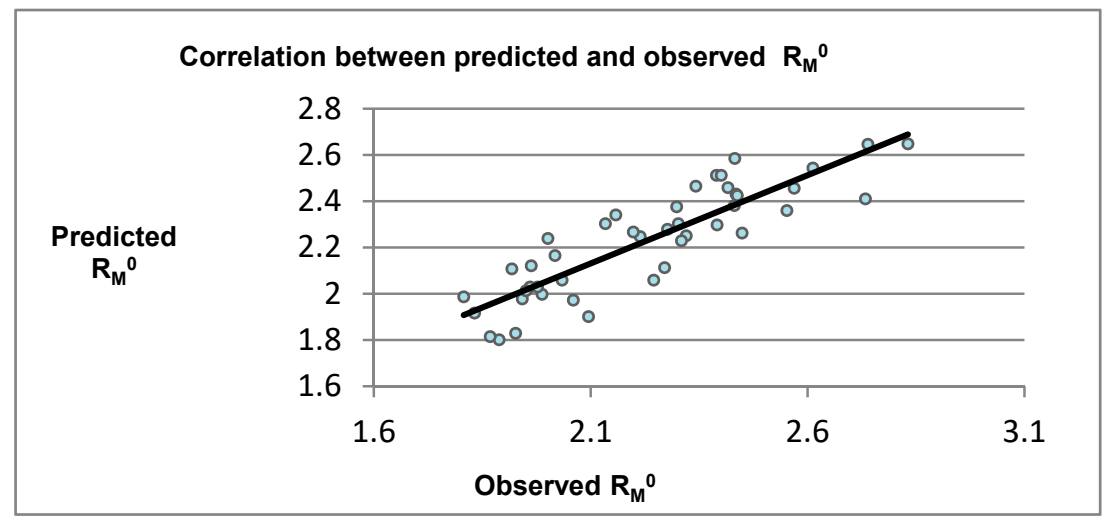

Figure 1. Plot showing correlation between observed and predicted $R_{M}{ }^{0}$, using multiple linear regression (MLR).

Based on reported studies, and the difference in $\mathrm{r}^{2}$ obtained by MLR and NNR (that suggest the presence of another parameter that correlates with $R_{M}$ ), principal component analysis (PCA) was performed. Principal components (PC) for $\mathrm{R}_{\mathrm{M}}$ were computed [30]. Using PC values, a new parameter, which presumably contained relevant information was created by dividing each PC to $R_{M}$ [31]. This newly obtained parameter was used in the clustering technique in order to identify common characteristics in the 44 studied compounds regarding lipophilicity. The lipophilicity space was computed using the clustering variable as the $\mathrm{z}$ coordinate, and the $\mathrm{x}$ and $\mathrm{y}$ variables were the parameters with the highest variability in respect to lipophilicity (see Figure 2). 


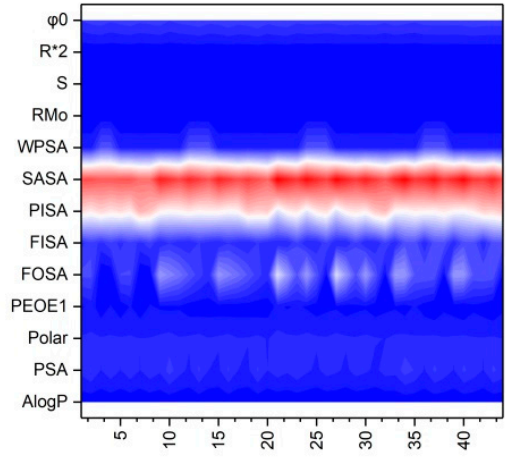

a
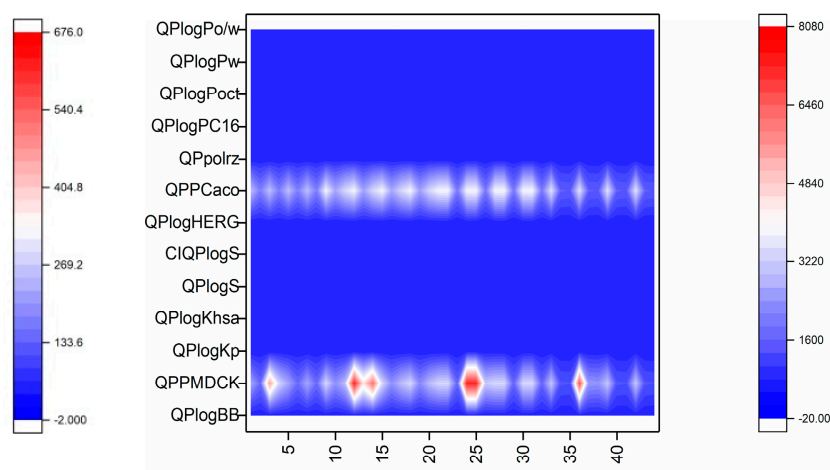

b

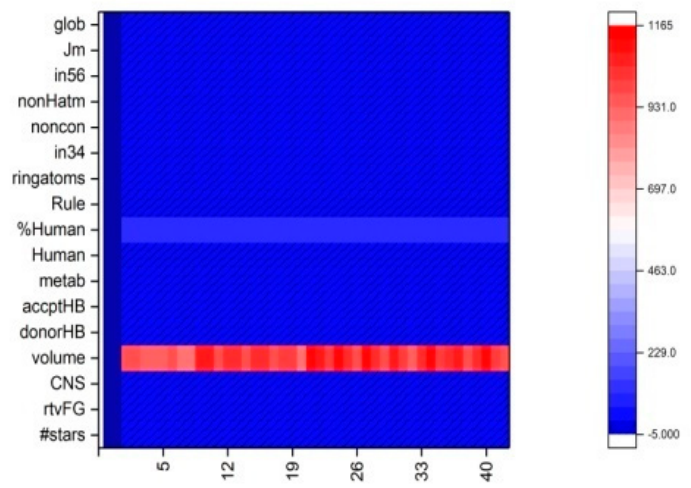

C

Figure 2. Compounds' (\#44) lipophilicity and drug-like properties represented as heatmaps; (a) RMo values for each compound represented together with some computed lipophilicity-related descriptors. (b) QPlog-related properties for each compound. (c) Drug-like properties for each compound.

Lipophilicity related parameters-isocratic retention factor $\left(R_{M}\right)$, relative lipophily $\left(R_{M}{ }^{0}\right)$, slope $(b)$, chromatographic hydrophobic index $\left(\varphi_{0}\right)$, together with some computed descriptors-are represented in Figure 2a.

A component of total solvent accessible surface area (SASA) was computed for $\mathrm{N}, \mathrm{O}, \mathrm{H}$ on heteroatoms (FISA), hydrophobic component of the SASA (FOSA), total positive van der Waals surface area (PEOE1), polarizability (polar), polar surface area (PSA), and partition coefficient (AlogP). SASA and FOSA showed considerable variability along the set of compounds. All these parameters are in the range of druggability (Figure 2a). QPlog-related parameters, like lipophilicity, showed relatively constant values for all compounds. Exceptions were noted at the predicted apparent Caco-2 cell permeability, in nm/s (QPPCaco), and predicted apparent Mandin Darby Canine Kidney MDCK cell permeability, in nm/s (QPPMDCK). Overall compounds showed excellent membrane permeability-predicted properties (Figure $2 b$ ).

Drug-like properties, both experimental and computational, are excellent. There were no violations of drug-like criteria. Drug-like properties computed proved to be constant for all compounds with one exception: The molecular volume of each compound apparently had no effect on druggability. Also, $\%$ human oral absorption, even if it had a constant value along the compound series, had a different dimensionality when compared with the other parameters (Figure 2c).

A pharmacophore model was computed by setting $\mathrm{R}_{\mathrm{M}}{ }^{0}$ as the dependent variable in order to explain $90 \%$ of the observed $\mathrm{R}_{\mathrm{M}}{ }^{0}$ values. The model was constructed using ARRR hypothesis (A-H acceptor; R-aromatic ring). Model cartesian coordinates are: $\mathrm{x}-4.12, \mathrm{y}-1.95, \mathrm{z} 0.00 \mathrm{R} 5 \mathrm{x}-0.03, \mathrm{y}-1.98$, z 0.00; A2x 5.29, y 0.75, z 0.00R8x 2.75, y 3.49, z 0.00. The pharmacophore model is showed in Figure 3. 

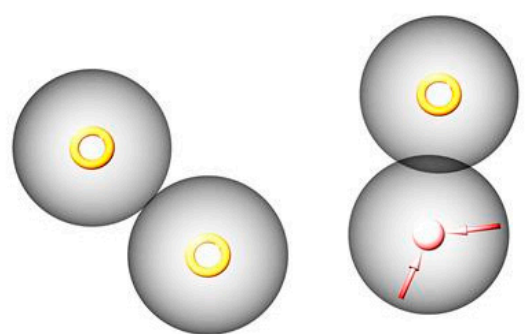

Figure 3. Pharmacophore model. Hydrogen acceptor—pink arrow. Aromatic groups—orange rings.

Clustering based on $\mathrm{R}_{\mathrm{M}}{ }^{0}$ principal component analysis was performed (Figure 4). PC1 and PC2 was computed. Hierarchical clustering analysis showed four clusters corresponding to the discussed retention factors. Clusters obtained are similar to the peaks obtained by representing $R_{M}{ }^{0}$ for all compounds as a scatter plot (see Supplementary Materials). Acetylated compounds seem to form a distinct strong group of clusters with higher densities.

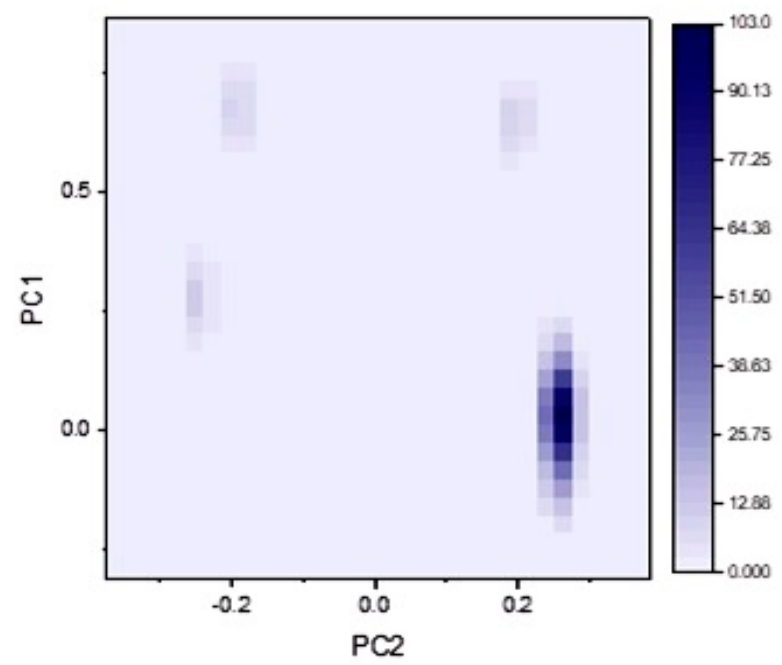

Figure 4. Heat map showing density clustering of all retention factors for thiazole chalcone and flavone derivatives. One main cluster is observed consecutively with three minor ones.

\section{Materials and Methods}

Thiazole chalcones, flavanones, flavones, 3-hydroxyflavones, and their acetylated derivatives have been previously synthesized by us. Thiazole chalcones were obtained by Claisen-Schmidt condensation of thiazole aldehydes with substituted acetophenones in ortho and/or para positions with hydroxy or methoxy groups [32]. By the cyclization of ortho hydroxychalcones with concentrated sulphuric acid [33], sodium acetate [34], or glacial acetic acid [35], the corresponding thiazole flavanones were synthesized. Flavones were obtained by oxidative cyclization of ortho hydroxyl/methoxychalcones with iodine in dimethylsulfoxide [36]. The 3-hydroxyflavones were synthesized by using urea-hydrogen peroxide complex or hydrogen peroxide in the presence of sodium hydroxide [37]. The acetylated derivatives of hydroxyl substituted compounds were obtained by treatment with acetic anhydride in the presence of pyridine [38]. The structure of synthesized compounds is presented in Supplementary Materials.

\subsection{Experimental Evaluation}

Reversed-phase thin layer chromatography (RP-TLC) was carried out using aluminum plates silica gel coated with fluorescent indicator RP-18F254s. The plates were purchased from Merck Millipore. Spots were visualized in UV light at 254 and $365 \mathrm{~nm}$. Analytical grade isopropanol used in the experiment was purchased from Merk. The retention factor $\left(\mathrm{R}_{f}\right)$ values obtained by RP-TLC 
were used for $R_{M}$ parameters (isocratic retention factor) and were calculated with the Bate-Smith and Westall equation [11]:

$$
\mathrm{R}_{\mathrm{M}}=\log \left[\left(1 / \mathrm{R}_{f}\right)-1\right]
$$

Based on the linear relationship between $R_{M}$ values and the concentration of the organic solvent in the mobile phase (Sosczewinski-Wachtmeister equation), three lipophilicity parameters were calculated: (a) $\mathrm{R}_{\mathrm{M}}{ }^{0}$ (which corresponds to $0 \%$ methanol in the mobile phase); (b) which represents the slope, and (c) which represents the volume fraction of methanol in the mobile phase [11]: $R_{M}=R_{M}{ }^{0}+b C$

The chromatography hydrophobic index, $\varphi_{0}$, was calculated using the following equation [19]:

$$
\varphi_{0}=\mathrm{R}_{\mathrm{M}}^{0} / b \text {. }
$$

RP-TLC experiments were performed for 20 thiazole chalcones, 4 flavanones, 4 flavones, 4 3-hydroxyflavones, and 12 acetylated derivatives. Compounds were divided in 3 groups: (1) thiazole chalcones with hydroxyl or methoxy groups (20 compond, 1a-t), (2) thiazole flavanones, flavones, and 3-hydroxyflavones (12 compounds, $\mathbf{2 a - d , 3 a - h ) , ~ a n d ~ ( 3 ) ~ a c e t y l a t e d ~ d e r i v a t i v e s ~ ( 1 2 ~ c o m p o u n d s , ~ 4 a - 1 ) . ~}$ TLC plates were prepared using a stationary phase and a mixture of isopropanol-water as the mobile phase. For every compound, parameters were determinated for five concentrations. For chalcones, flavanones, flavones, and 3-hydroxyflavones, concentration ratios of the isopropanol-water mixture were $55 \%, 60 \%, 65 \%, 70 \%$, and $75 \%$, respectively. Concentrations for acetylated derivatives were $50 \%$, $55 \%, 60 \%, 65 \%$, and $70 \%$, respectively.

The 44 compounds were dissolved in dichlormethane $(1 \mathrm{mg} / \mathrm{mL})$ and every solution was applied manually with a capillary four times. Distance between every compound was $1 \mathrm{~cm}$ and the migration distance was $8 \mathrm{~cm}$ in all cases. Elution of compounds was performed in a developing chamber previously saturated with mobile phase for $30 \mathrm{~min}$ at room pressure and temperature. After complete elution, spots were visualized in UV light at wavelengths of $254 \mathrm{~nm}$ and $365 \mathrm{~nm}$ (see Supplementary Materials). To reduce the errors that may occur, for each concentration three measurementswere made.

Regular retention behavior of investigated compounds was observed. Retention decreases with increasing concentration of organic modifier in the mobile phase. Based on retention factor $\left(R_{f}\right)$, the relative lipophily $\left(\mathrm{R}_{\mathrm{M}}{ }^{0}\right)$, slope $(b)$, chromatographic hydrophobic index $\left(\varphi_{0}\right)$, and scores of principal component $\left(\mathrm{PC} 1 / \mathrm{R}_{\mathrm{M}}\right)$ were determined.

\subsection{Computational Evaluation}

Schrodinger computational package [39] was used for descriptors computation and the pharmacophore model, while Origin software was used for statistical analysis and representation of data.

In order to computationally assess the lipophilicity and, consecutively, the drug-like properties of the discussed compounds, in silico 3D models were generated starting from 2D chemical formulas. SDF file format was used to store 3D chemical information. Energy minimization, potential energy calculus, and protonation at $310 \mathrm{~K}$ at pH 7.4, respectively, were performed using MM2 force field using TINKER software package [40]. Chemical descriptors assessing the lipophilicity were computed using the Schrodinger software.

\section{Conclusions}

From the 44 synthesized compounds, the highest retention capacity was shown by chlorinesubstituted para hydroxyl-chalcone. Regardless of the basic structure, chlorine substitution of phenylthiazole caused an increase in lipophilicity of the molecule, and the hydroxyl group increased the hydrophilia of the synthesized compounds. Flavanones have a lower retention capacity than the corresponding flavones. Based on the results obtained, it can be stated that lipophilicity is influenced by the basic structure of the molecule and by the nature, position, and number of functional groups on the basic structure. Aromatic groups and $\mathrm{H}$-accepting groups seem to be crucial in explaining 
lipophilicity of these compounds. All the discussed compounds computationally showed excellent drug-like properties, with good biological membrane absorption factors. Lipophilicity has a crucial role in the biological activity of the concerned compounds and measuring or computing the discussed descriptors represent a key component in the study of drug-like properties of the molecules.

Supplementary Materials: Supplementary Materials are available online.

Author Contributions: T.C. and C.L. established the conceptual framework and assembled the paper. The literature screening was performed by T.C. C.L. performed the computational part and the experimental part was performed by T.C. and I.L.

Funding: This research received no external funding.

Conflicts of Interest: The authors declare no conflict of interest.

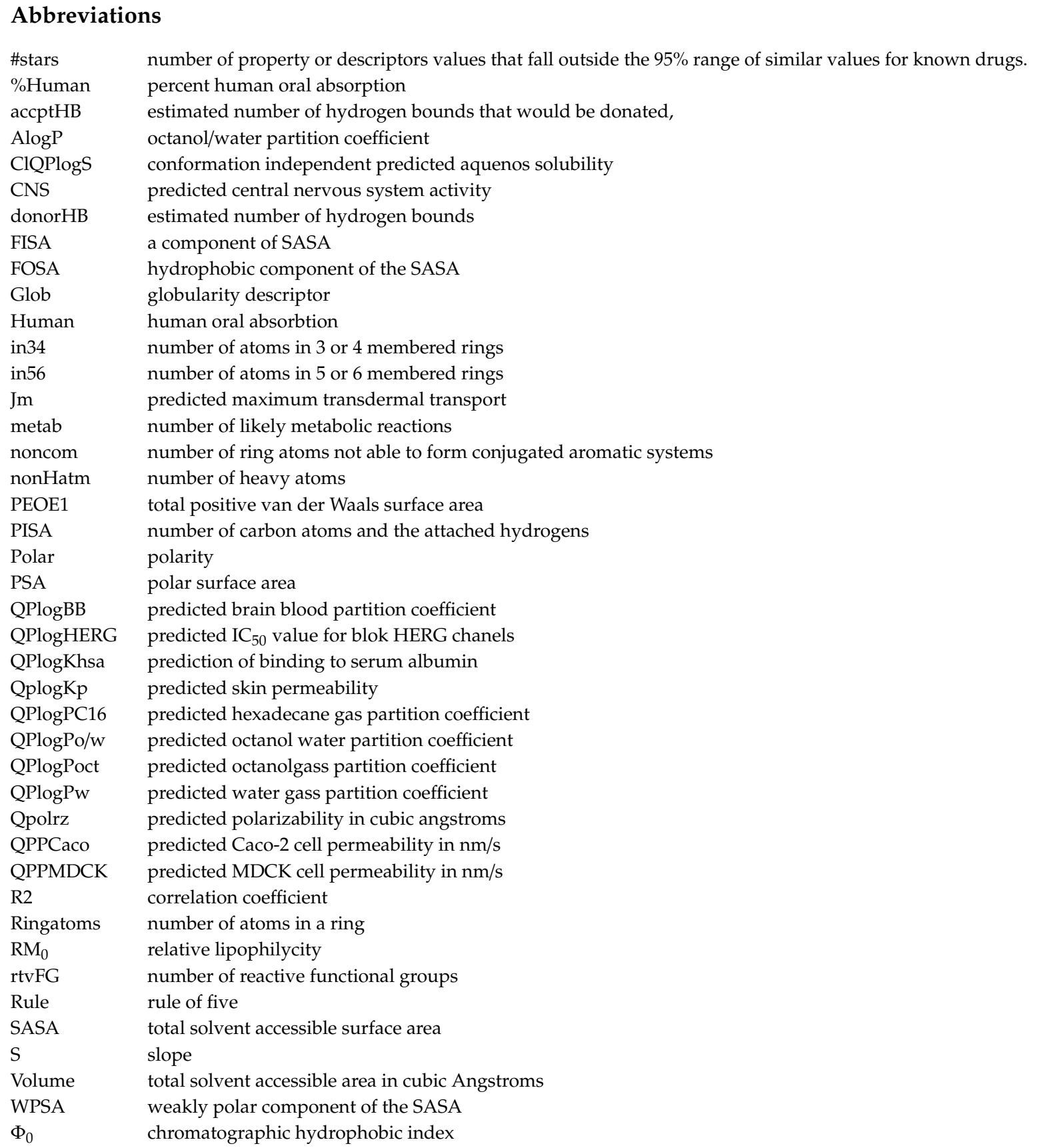




\section{References}

1. Tóth, G.; Mazák, K.; Hosztafi, S.; Kökösi, J.; Noszál, B. Species-specific lipophilicity of thyroid hormones and their precursors in view of their membrane transport properties. J. Pharm. Biomed. Anal. 2013, 76, 112-118. [CrossRef]

2. Jevrić, L.R.; Karadžić, M.Ž.; Mandić, A.I.; Podunavac Kuzmanović, S.O.; Kovačević, S.Z.; Nikolić, A.R.; Oklješa, A.M.; Sakač, M.N.; Penov Gaši, K.M.; Stojanović, S.Z. Lipophilicity estimation and characterization of selected steroid derivatives of biomedical importance applying RP HPLC. J. Pharm. Biomed. Anal. 2017, 134, 27-35. [CrossRef]

3. Mazák, K.; Kökösi, J.; Naszál, B. Lipophlicity of zwitterions and related species: a new insight. Eur. J. Pharm. Sci. 2011, 44, 68-73. [CrossRef]

4. Santos, Á.; Soares, Y.X.; Cravo, S.; Tiritan, M.; Reis, S.; Afonso, C.; Fernandes, C.; Pinto, M. Lipophilicity assessment in drug discovery: experimental and theoretical methods applied to xanthone derivatives. J. Chromatogr. B 2018, 1072, 182-192. [CrossRef] [PubMed]

5. Klose, M.; Theiner, S.; Varbanov, H.; Hoefer, D.; Pichler, V.; Galanski, M.; Meier-Menches, S.; Keppler, B. Development and validation of liquid chromatography-based methods to assess the lipophilicity of citotoxic Platinum (IV) complexes. Inorganics 2018, 6, 130. [CrossRef]

6. ączkowski, K.; Biernasiuk, A.; Baranowska-ączkowska, A.; Zavyalova, O.; Redka, M.; Malm, A. Synthesis, lipophilicity determination, DFT calculation, antifungal and DPPH radical scaverging activities of tetrahydrothiophen-3-one based thiazole. J. Mol. Struct. 2018, 1171, 717-725. [CrossRef]

7. Malinowska, I.; Studziński, M.; Malinoski, H. Change of 1,2,4-triazole retention and lipophilicity descriptor values in RP-TLC and MLC-TLC systems in the presence of an external magnetic field. J. Planar Chromatogr. 2017, 30, 106-112. [CrossRef]

8. Pastuszko, A.; Majchrzak, K.; Czyz, M.; Kupcewicz, B.; Budzisz, E. The synthesis, lipophilicity and cytotoxic effects of new ruthenium(II) arene complexes with chromone derivatives. J. Inorg. Biochem. 2016, 159, 133-141. [CrossRef]

9. Moreira, J.; Ribeiro, D.; Silva, P.; Nazareth, N.; Monteiro, M.; Palmeira, A.; Saraiva, L.; Pinto, M.; Bousbaa, H.; Cidade, H. New alcoxy flavone derivatives targeting caspases: Synthesis and antitumor activity evaluation. Molecules 2019, 24, 129. [CrossRef]

10. Bakht, M.A.; Alajmi, M.F.; Alam, P.; Alam, A.; Alam, P.; Aljarba, T.M. Theoretical and experimental study on lipophilicity and wound healing activity on ginger compounds. Asian Pac. J. Trop. Biomed. 2014, 4, 329-333. [CrossRef] [PubMed]

11. Bhatt, N.; Chavada, V.; Sanyal, M.; Shrivastav, P. Influence of organic modifier and separation modes for lipophilicity assessment of drugs using thin layer chromatography indices. J. Chromatogr. A 2018, 1571, 223-230. [CrossRef] [PubMed]

12. Numviyimana, C.; Chmiel, T.; Kot-Wasik, A.; Namieśnik, J. Study of pH temperature effect on lipophilicity of catechol-containing antioxidants by reversed phase liquid chromatography. Microchem. J. 2019, 145, 380-387. [CrossRef]

13. Vastag, G.; Apostolov, S.; Matjević, B. Prediction of lipophilicity and pharmacokinetics of chloroacetamides by chemometric approach. Iran. J. Pharm. Res. 2018, 17, 100-114. [PubMed]

14. Xin, X.; Zhang, M.; Li, X.; Lai, F.; Zhao, G. Biocatalytic synthesis of acylated derivatives of troxerutin: Their bioavailability and antioxidant properties in vitro. Microb. Cell Fact. 2018, 17, 130. [CrossRef]

15. Linton, M.A.; Burke, B.; Johnson, T.; Ninkovic, S.; Gajiwala, K.; Richardson, P.; Le, P. Effect of water solvation on the lipophilicity of isomeric pyrimidine-carboxamides. Bioorg. Med. Chem. 2015, 23, 2408-2413. [CrossRef] [PubMed]

16. Martel, S.; Begnaud, F.; Schuler, W.; Gillerat, F.; Oberhauser, N.; Nurisso, A.; Carrupt, P.A. Limits of rapid log $\mathrm{P}$ determination methods for highly lipophilic and flexible compounds. Anal. Chim. Acta 2016, 915, 90-101. [CrossRef] [PubMed]

17. Liang, C.; Lian, H.-Z. Recent advances in lipophilicity measurement by reversed-phase high-performance liquid chromatography. Trends Anal. Chem. 2015, 68, 28-36. [CrossRef]

18. Mc Bride, E.; Kretsch, A.; Garibay, L.; Brigance, K.; Frey, B.; Buss, B.; Verbeck, G. Rapid experimental and computational determination of phenethylamine drug analogue lipophilicity. Forensic Chem. 2016, 1, 58-65. [CrossRef] 
19. Rageh, A.H.; Atia, N.N.; Abdel-Rahman, A.M. Lipophilicity estimation of statins as a decisive physicochemical parameter for their hepato-selectivity using reversed-phase thin layer chromatography. J. Pharm. Biomed. Anal. 2017, 142, 7-14. [CrossRef] [PubMed]

20. Karadžić, M.; Lončar, D.; Benedeković, G.; Kovačević, I.; Popsavin, V.; Kocačević, S.; Jevrić, L.; Podunavac-Kuzmanavić, S. A comparative study of chromatographic behavior and lipophilicity of selected natural styryl lactones, their derivatives and analogues. Eur. J. Pharm. Sci. 2017, 105, 99-107. [CrossRef] [PubMed]

21. Reddy, M.V.B.; Su, C.R.; Chiou, W.F.; Liu, Y.N.; Chen, R.Y.H.; Bastaw, K.F.; Lee, K.H.; Wu, T.S. Design, synthesis and biological evaluation of Mannich bases of heterocyclic chalcone analogs as cytotoxic agents. Bioorg. Med. Chem. 2018, 16, 7358-7370. [CrossRef]

22. Evangelista, F.C.G.; Bandeira, M.O.; Silva, G.D.; Silva, M.G.; Andrade, S.N.; Marques, D.R.; Silva, L.M.; Castro, W.V.; Santos, F.V.; Viana, G.H.R.; et al. Synthesis and in vitro evaluation of novel triazole/azide chalcones. Med. Chem. Res. 2017, 26, 27-43. [CrossRef]

23. Venkataramana Reddy, P.O.; Hridhay, M.; Nikhil, K.; Khan, S.; Jha, P.N.; Shah, K.; Kumar, D. Synthesis and invastigations into the anticancer and antibacterial activity studies of $\beta$-carboline chalcones and their bromide salts. Bioorg. Med. Chem. Lett. 2018, 28, 1278-1282. [CrossRef]

24. Mellado, M.; Madrid, A.; Reyna, M.; Weinstein-Oppenheimer, C.; Mella, J.; Sales, C.; Sanchez, E.; Cuellar, M. Synthesis of chalcones with antiproliferative activity on the SH-5Y5Y neuroblastoma cell line: Quantitative Structure-Activity Relationship Models. Med. Chem. Res. 2018, 27, 2414-2425. [CrossRef]

25. Constantinescu, T.; Lungu, C.N. Chalcones lack of specificity: Tubuline, a multitargeted molecule. RJLBPCD 2018, 4, 260-268.

26. Chen, P.Y.; Wang, T.P.; Chiang, M.Y.; Huang, K.S.; Tzeng, C.C.; Chen, Y.L.; Wang, E.C. Environmentally benign syntheses of flavanones. Tetrahedron 2011, 67, 4155-4160. [CrossRef]

27. Lahyani, A.; Trabelsi, M. Ultrasonic-assisted synthesis of flavones by oxidative cyclization of 2'-hydroxychalcones using iodine monochloride. Ultrason. Sonochem. 2016, 31, 626-630. [CrossRef] [PubMed]

28. Pawar, C.D.; Sarkate, A.P.; Karnik, K.S.; Bahekar, S.S.; Pansare, D.N.; Shelke, R.N.; Jawale, C.S.; Shinde, D.B. Synthesis and antimicrobial evaluation of novel ethyl 2-(2-(4-substituted)acetamido)4-subtituted-thiazole-5-carboxylate derivatives. Bioorg. Med. Chem. Lett. 2016, 26, 3525-3528. [CrossRef]

29. Lungu, C.N.; Diudea, M.V.; Putz, M.V.; Grudzinski, I.P. Linear and branched PEIs (polyethylenimines) and their property space. Int. J. Mol. Sci. 2016, 17, 555. [CrossRef] [PubMed]

30. Lungu, C.N. C-C Chemokine receptor type 3 inhibitors: bioactivity prediction using local vertex invariants based on thermal conductivity layer matrix. Studia UBB Chemia 2018, 1, 177-188. [CrossRef]

31. Majumdar, S.; Basak, S.C.; Lungu, C.N.; Diudea, M.V.; Grunwald, G.D. Mathematical structural descriptors and mutagenicity assessment: A study with congeneric and diverse datasets. SAR QSAR Environ. Res. 2018, 29, 579-590. [CrossRef]

32. Raghav, N.; Kaur, R. Chalcones, semicarbazones and pyrazolines as inhibitors of cathepsins B, H and L. Int. J. Biol. Macromol. 2015, 80, 710-724. [CrossRef] [PubMed]

33. Bano, S.; Javed, K.; Ahmad, S.; Rathish, I.G.; Singh, S.; Chaitanya, M.; Arunasree, K.M.; Alam, M.S. Synthesis of some novel chalcones, flavanones and flavones and evaluation of their anti-inflammatory activity. Eur. J. Med. Chem. 2013, 65, 51-59. [CrossRef]

34. Safavi, M.; Esmati, N.; Ardestani, S.K.; Emami, S.; Ajdari, S.; Davoodi, J.; Shafiee, A.; Foroumadi, A. Halogenated flavanones as potential apoptosis-inducing agents: synthesis and biological activity evaluation. Eur. J. Med. Chem. 2012, 58, 573-580. [CrossRef] [PubMed]

35. Cabrera, M.; Simoens, M.; Falchi, G.; Lavaggi, M.L.; Piro, O.E.; Castellano, E.E.; Vidal, A.; Azqueta, A.; Monge, A.; de Ceráin, A.L.; et al. Synthetic chalcones, flavanones, and flavones as antitumoral agents: Biological evaluation and structure-activity relationships. Bioorg. Med. Chem. 2007, 15, 3356-3367. [CrossRef] [PubMed]

36. Chimenti, F.; Fioravanti, R.; Bolasco, A.; Chimenti, P.; Secci, D.; Rossi, F.; Yáñez, M.; Orallo, F.; Ortuso, F.; Alcaro, S.; et al. A new series of flavones, thioflavones, and flavanones as selective monoamine oxidase-B inhibitors. Bioorg. Med. Chem. 2010, 18, 1273-1279. [CrossRef] [PubMed]

37. Gunduz, S.; Goren, A.C.; Ozturk, T. Facile syntheses of 3-hydroxyflavones. Org. Lett. 2012, 14, $1576-1579$. [CrossRef] 
38. Ghuarpure, M.; Choudhary, R.; Ingle, V.; Juneja, H. Synthesis of new series of 3-hydroxy/acetoxy-2phenyl-4H-chromen-4-ones and their biological importance. J. Chem. Sci. 2013, 125, 575-582. [CrossRef]

39. Lungu, C.N.; Diudea, M.V.; Putz, M.V. Ligand shaping in induced fit docking of Mra Y inhibitors. Polynomial discriminant and laplacian operator as biologicaly activity descriptors. Int. J. Mol. Sci. 2017, 18, 1377. [CrossRef] [PubMed]

40. Diudea, M.V.; Lungu, C.N.; Nagy, C.L. Cube-Rhombellane related structures: A drug perspective. Molecules 2018, 23, 2533. [CrossRef] [PubMed]

Sample Availability: Samples of the compounds are available from the authors.

(C) 2019 by the authors. Licensee MDPI, Basel, Switzerland. This article is an open access article distributed under the terms and conditions of the Creative Commons Attribution (CC BY) license (http://creativecommons.org/licenses/by/4.0/). 